R.A. Browne MD FFARCS(E) FRCP(C), S. McDonald MD FRCs(C)

\section{A vapourizer interlocking system}

The Canadian Standards Association (CSA) recommends that vapourizers on anaesthetic machines should be mounted so as to prevent more than one vapourizer being in use at a time. '

When balothane and enflurane (administered using Ohio vapourizers) were the main intalational agents used in our hospital, we accommodated this recommendation by adding an interlock bar sold by Ohio, which, by using the flanged heads on the vapourizers, allowed the use of only one vapourizer at any time.

With the introduction of isoflurane in 1981 , we decided to use all three agents, so that the twovapourizer interlock system was no longer satisfactory. We devised a new system, the Anaeslock* (Figures 1-3).

The Anaeslock consists of a solid bar of aluminium or stainless steel which contains a cam situated opposite each vapourizer. Each cam has an opening or gate in it, which allows the flange on the vapourizer head to pass through it. Varying the position of the gate in each cam ensures that only one vapourizer can be turned on at any time. The Anaeslock can be used to control two or three vapourizers arranged in series. It is attached by bolts to the horizontal back bar of the machine. As the Anaeslock bar is rotated, an audible click occurs, indicating that the chosen vapourizer can be used. Visible indication as to which vapourizer is interlocked is shown by a label on the front of the bar, e.g., halothane, isoflurane, enflurane.

In accordance with Canadian Standards Association suggestions, ${ }^{2}$ the labels have been placed so

*Available from: Southmedic Inc., P.O. Box 7278, Ancaster, Ontario, Canada L9G 3N6.

From the Departments of Anaesthesia and Surgery, McMaster University, Hamilton, Ontario

Address carrespondence to: Dr. R.A. Browne, Anaesthetic Department, Hamilton General Hospital, 237 Barton Street East, Hamilton, Ontario, L8L 2X2. that vapourizers are arranged according to increasing vapour pressures - from left to right enflurane, isoflurane and halothane.

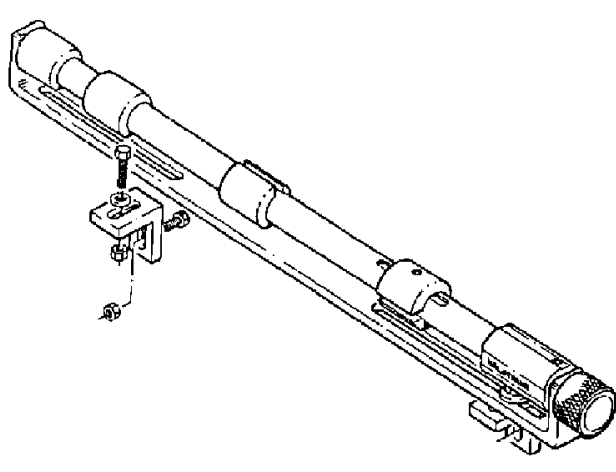

FIGURE 1 Anaeslock detached

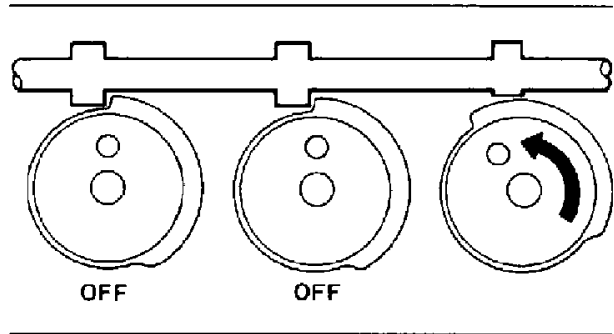

FIGURE 2 Vapourizers with Anzeslock showing interlocking principle.

Advantages of the Anaeslock are:

1 It can be used to control up to three vapourizers in series so that only one can be used at any time. The 3-cam system will work with two vapourizers, while the third vapourizer can be added later when convenient.

2 The vapourizers are fixed and not removed, obviating accidental upset and spilling of fluid. 


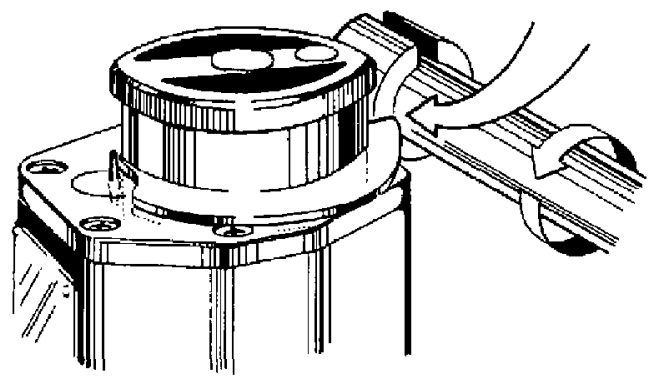

FIGURE 3 Gate shown closed

3 The anaesthetic circuit is not violated in any way, thus obviating circuit leaks which may occur with other systems in which the vapourizers are exchanged.

4 Simplicity of the system using a cam with a gate in it which is easily rotated manually to the desired position.

5 The system is very durable and should last for many years.

6 The Anaeslock can be placed on the anaesthetic machine or removed in a few minutes, using a wrench.

7 An add-on adapter, with flange, has also been devised which converts Benson and Cyprane vapourizers for use with the Anaeslock. The adapter fits over the head of Benson and Cyprane vapourizers and in effect adds a flange for interlocking.

8 Each Anaesiock and add-on adapter has C.S.A. "Special Acceptance."

\section{References}

1 Canadian Standards Association. Standard Z168.3M1980 Continuous-Flow Inhalational Anaesthetic Apparatus (Anacsthetic Machines) for Medical Use. Section 12.3.5 p. 15 .

2 lbid. Section 12.4.1(2) p. 15 